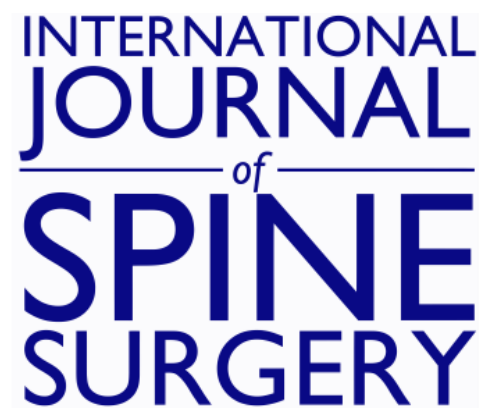

\title{
Paraplegia Secondary to Plasmacytoma of the Lumbar Spine
}

\author{
K.C. ESEONU, S.D. MIDDLETON and A.S. SUBRAMANIAN
}

Int J Spine Surg 2020, 14 (4) 559-562

doi: https://doi.org/10.14444/7074

http://ijssurgery.com/content/14/4/559

This information is current as of April 26, 2023.

Email Alerts Receive free email-alerts when new articles cite this article. Sign up at: http://ijssurgery.com/alerts 


\title{
Paraplegia Secondary to Plasmacytoma of the Lumbar Spine
}

\author{
K.C. ESEONU, MSc (Oxon), ${ }^{1}$ S.D. MIDDLETON, MBCHB, ${ }^{2}$ A.S. SUBRAMANIAN ${ }^{2}$ \\ ${ }^{I}$ Royal National Orthopaedic Hospital, Stanmore, United Kingdom, ${ }^{2}$ Department of Orthopaedic Spinal Surgery, Royal Infirmary of Edinburgh, Edinburgh, \\ Scotland
}

\begin{abstract}
Background: Solitary plasmacytoma of bone has a predilection for the axial skeleton, most commonly affecting the thoracic spine. We report the case of a patient who presented with acute on chronic back pain and developed severe neurologic deficits within several hours of admission secondary to a pathologic fracture of L1.

Methods: The patient underwent an urgent magnetic resonance imaging scan followed by T12 to L2 posterior decompression and T11 to L3 posterior instrumented stabilization. Subsequent histopathologic examination of specimens taken at the time of surgery found this to be secondary to a plasmacytoma affecting the lumbar spine.

Results: At follow-up, recovery has been rapid and extensive, with the patient remaining under hematologic review because of the risk for developing multiple myeloma.

Conclusions: The unique features of this case relate to the location of the plasmacytoma and the neurologic signs; to our knowledge this is the first reported case in the literature of paraplegia secondary to a lumbar spine plasmacytoma.

Lumbar Spine
\end{abstract}

Keywords: plasmacytoma, spinal decompression, neurological compromise, spinal tumour/tumor

\section{INTRODUCTION}

Plasmacytoma is a malignant proliferation of plasma cells, accounting for approximately $5 \%$ of plasma cell neoplasms. They are subdivided into solitary plasmacytoma of bone (SPB) and extramedullary plasmacytoma. Patients with plasmacytomas can develop multiple myeloma (MM), and it is therefore considered a precursor to MM. ${ }^{1}$ SPB may rarely lead to pathologic vertebral body fracture with subsequent instability and spinal cord compression. It most commonly affects the axial skeleton with a predilection for the thoracic spine, but cases presenting with abnormal neurologic signs are restricted to case reports only. ${ }^{2-4}$ There are no case reports of SPB of the lumbar spine presenting with acute paraplegia.

We report the case of a patient with SPB affecting the lumbar spine which presented as an acute exacerbation of chronic back pain secondary to a pathologic fracture, with rapidly progressive neurologic dysfunction.

\section{CASE REPORT}

A 71-year-old retired physiotherapist was referred to the orthopaedic service with acute on chronic lower back pain. She had a past medical history of breast cancer (treated with mastectomy 20 years previously) and was independent with her mobility and activities of daily living.

She had attended her primary care physician several times during the past year with lower back pain. Despite her age and history of malignancy, only a plain radiograph was sought (Figure 1).

Her neurologic examination was entirely unremarkable. Current radiographs (Figure 2) revealed a new L1 compression fracture when compared to recent radiographs 2 months prior to presentation (Figure 1).

Overnight, she developed urinary retention and weakness in both legs with altered sensation at the level of L2/L3 bilaterally and absent sensation below L3. She also had absent perianal sensation and reduced anal tone. The patient was given intravenous dexamethasone and underwent urgent magnetic resonance imaging (MRI; Figure 3), which showed a fracture of $\mathrm{L} 1$ with posterior bulging, epidural infiltration, and extension into both pedicles in keeping with neoplastic involvement. There was marked compression of the dural sac.

The patient underwent urgent T12 to L2 posterior decompression and T11 to L3 posterior 


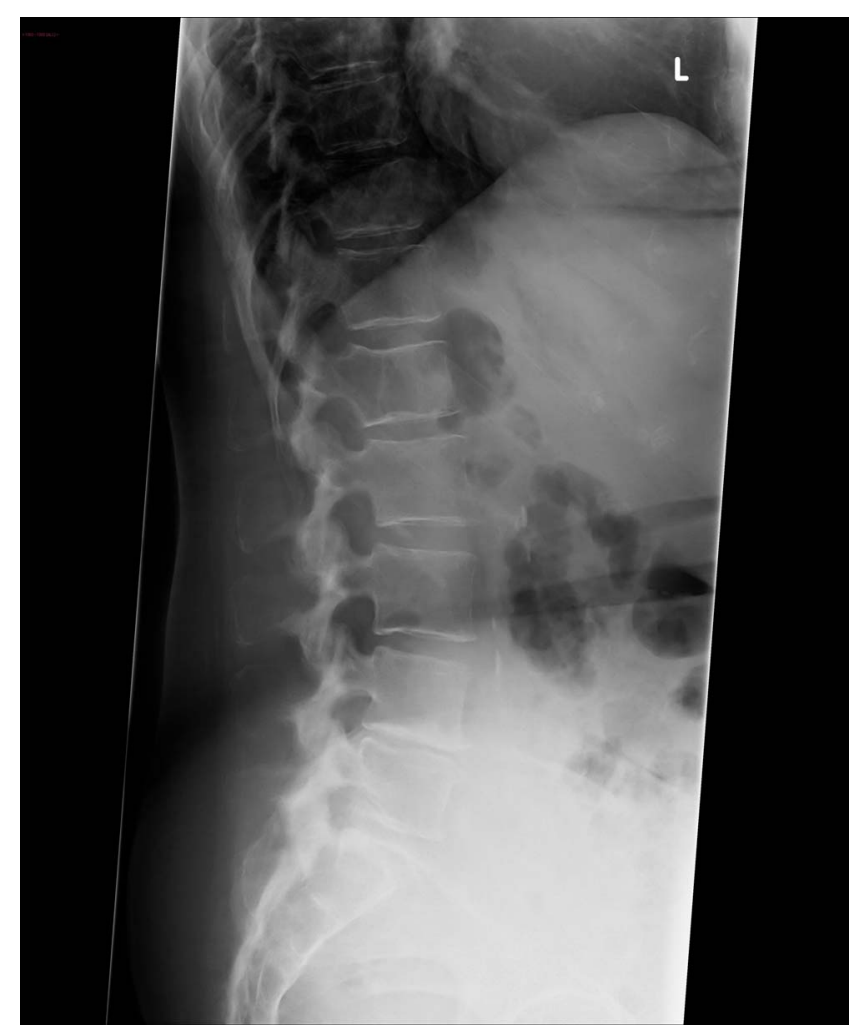

Figure 1. Lateral radiograph 2 months prior to presentation.

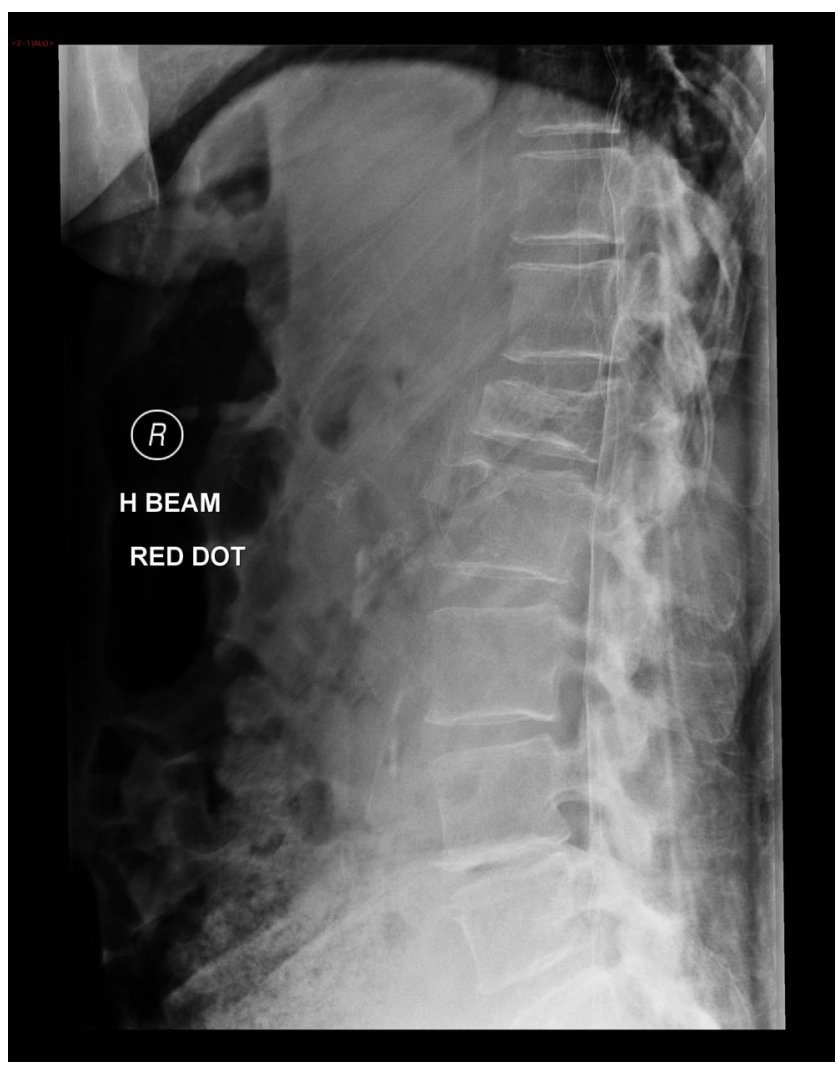

Figure 2. Lateral radiograph at the time of presentation to the emergency department.

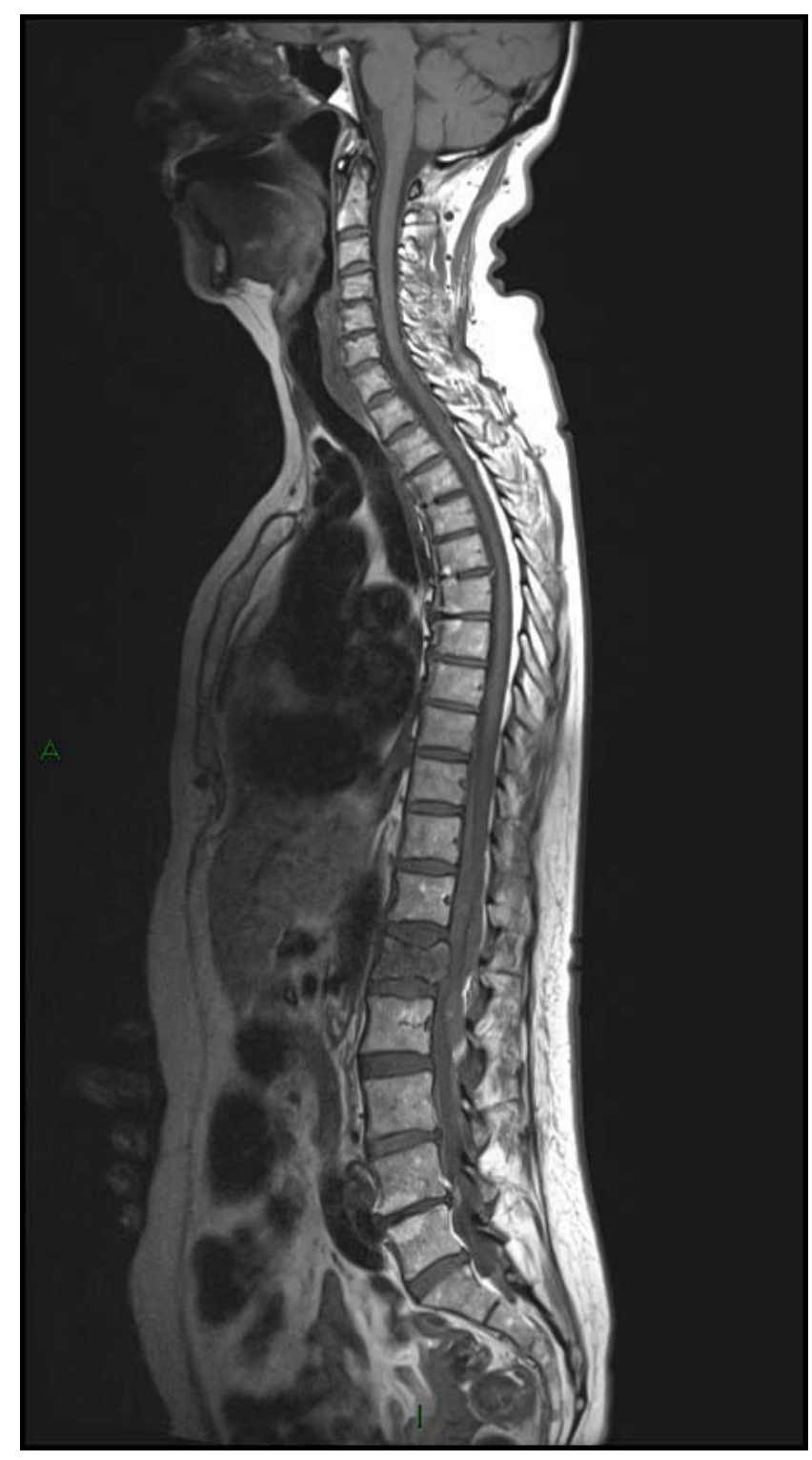

Figure 3. T1-weighted MEl image following onset of paraplegia.

instrumented stabilization (Figure 4). The intraoperative findings were of severe compression of the cord with a mixture of tumor tissue and hematoma from T11 to L2.

She underwent extensive postoperative investigations, including blood and urine protein electrophoresis; computed tomography scan of the chest, abdomen, and pelvis; skeletal survey; bone marrow biopsy; and a radionuclide bone scan (Figure 5), which were negative. Histopathologic examination of the intraoperative samples confirmed a plasmacytoma.

The patient made a remarkable recovery, and at 6month follow-up she mobilized without a stick. With regard to her bladder and bowel function, she has 


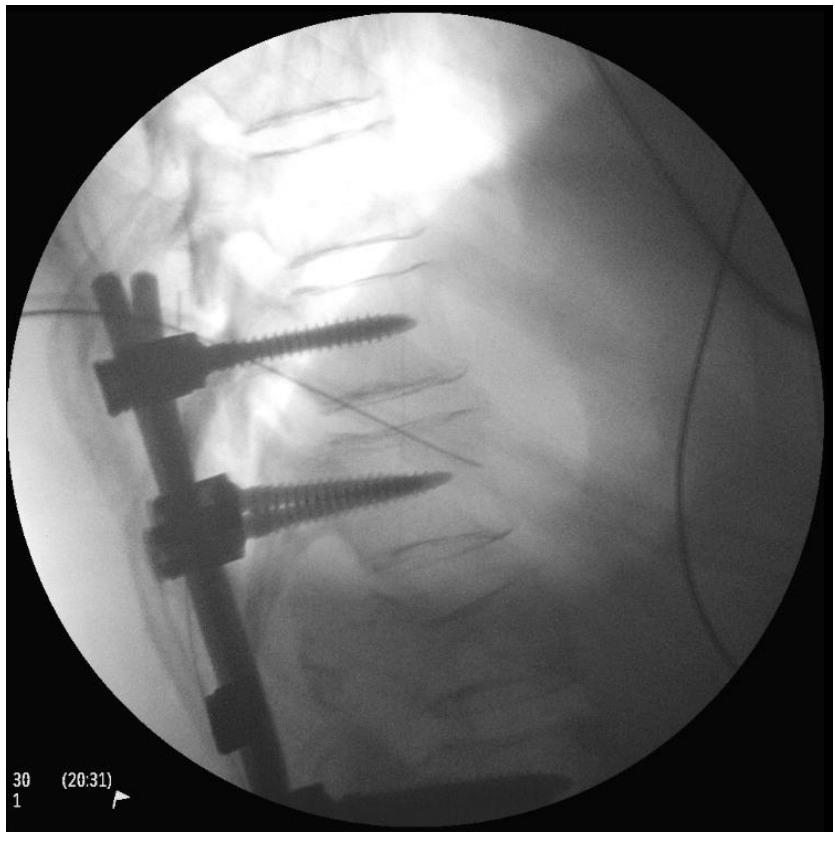

Figure 4. Intraoperative image intensifier films.

regained continence. Examination reveals reduced sensation in the L4 distribution on the right side, but is otherwise normal. She remains under hematologic review to detect the development of $\mathrm{MM}$, and her current immunoglobulin $\mathrm{G} \kappa$ paraprotein levels are slightly raised at $18 \mathrm{~g} / \mathrm{L}$. Postoperative radiographs are entirely satisfactory (Figure 6).

\section{DISCUSSION}

The prevalence of back pain in the United Kingdom is $36.1 \%$, and it is estimated to affect around one-third of the adult population each year. ${ }^{5}$ Of these, approximately $20 \%$ (1 in 15 of the population) will consult their primary care physician about their back pain. ${ }^{6}$

Back pain may be an initial manifestation of a serious underlying pathology, although less than $1 \%$ is attributable to malignancy. A recent systematic review investigates the evidence base behind the traditional "red flags." Of these, history of cancer increased the probability of malignancy to between $7 \%$ and $33 \%$, whereas older age, unexplained weight loss, and failure to improve after 1 month have posttest probabilities below 3\%. No other red flags could be identified as being predicative of malignancy. ${ }^{7}$

The National Institute for Health and Care Excellence recommends avoidance of radiographs in the investigation of lumbar back pain. ${ }^{8}$ The current guidelines recommend an MRI scan if there

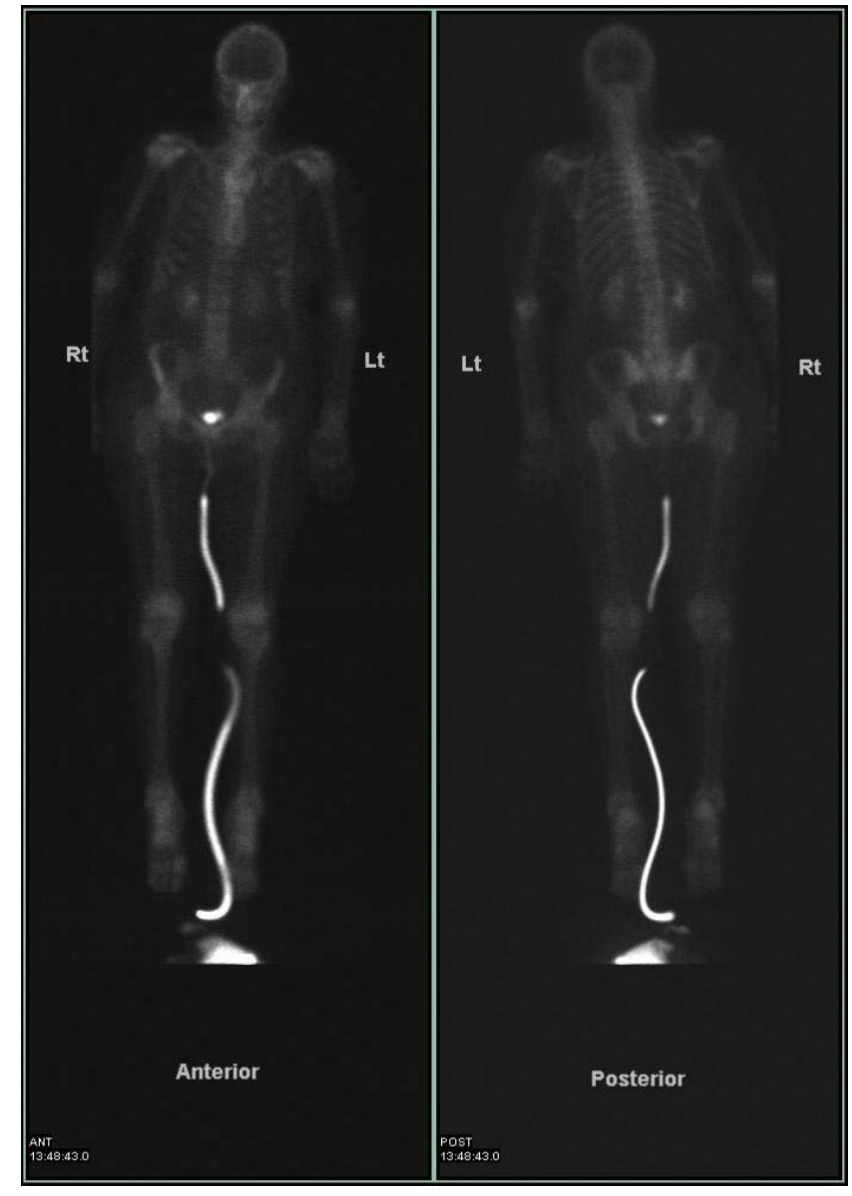

Figure 5. Postoperative radionuclide bone scan.

is suspicion of malignancy, fracture, infection, cauda equina, or inflammatory process.

This case highlights SPB as a potential cause of acutely deteriorating neurologic function in patients with back pain. It reaffirms the place of MRI as the first line of investigation when confronted with a patient with red flag symptoms and alerts clinicians to the importance of remaining vigilant when any patient with lower back pain seeks medical attention.

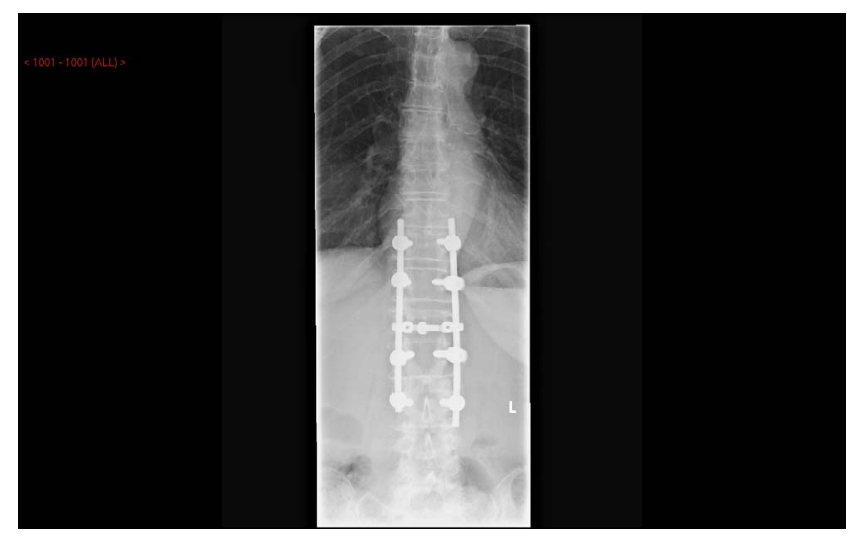

Figure 6. Lateral radiograph 6 months after operation. 
There are a number of case reports in the literature of SPB in the axial spine. There are reports of pathologic lesions in the cervical, thoracic, and lumbar spine. However, there is no consensus regarding surgical approach and perioperative strategies. Some authors justify radical surgery (total spondylectomy) with postoperative radiotherapy as a strategy to minimize local recurrence and the risk of conversion into $\mathrm{MM}$.

Huang et $\mathrm{al}^{9}$ published a consecutive series of 20 cases of SPB in the cervical spine that underwent surgical treatment. Twelve of these cases were Frankel neurologic grade $\mathrm{C}^{10}$ (sensation present, motor function present, but not useful; ASIA 2/3) or worse at the time of presentation. All their cases were managed using an anterior approach or a combined anterior and posterior approach in 1 stage. Neurologic function improved by 1 to 3 grades on the Frankel scoring system, and 14 of 20 patients had normal neurologic function by 3 months' follow-up

Röpke et $\mathrm{al}^{11}$ report a 64-year-old woman with SPB and resultant intermittent lower limb weakness and intermittently deranged urinary voiding under axial load in a case of thoracic SPB. Following urgent laminectomy, intralesional tumor removal and posterior stabilization (Th4-Th6), the patient regained full neurologic function.

To the best of our knowledge this is the first report of lumbar SPB presenting with acute paraplegia. This report demonstrates the potential for extensive recovery when treated expediently with surgical decompression and instrumented stabilization and supports the findings of the existing literature where neurologic function was significantly and rapidly improved following surgical decompression.

All patients presenting in this manner should also undergo thorough postoperative investigation to rule out $\mathrm{MM}$ or concurrent plasmacytomas, and require prolonged follow-up because of the risk of developing MM.

\section{REFERENCES}

1. Palumbo A, Anderson K. Multiple myeloma. $N$ Engl $J$ Med. 2011;364:1046-1060.
2. Takahashi T, Koshu K, Tominaga T, et al. Solitary plasmacytoma in the thoracic spine: two case reports. Neurosurg Rev. 1998;21:121-125.

3. Terada T. Solitary plasmacytoma of the thoracic vertebra presenting with sudden paraplegia and back pain: a pathologic case report. Pathol Onchol Res. 2011;17:167-169.

4. Baba H, Maezawa Y, Furusawa N, et al. Solitary plasmacytoma of the spine associated with neurological complications. Spinal Cord. 1998;36:470-475.

5. Raspe H, Matthis C, Croft P, et al. Variation in back pain between countries, the example of Britain and Germany. Spine (Phila Pa 1976). 2004;29:1017-1021.

6. Macfarlane GJ, Jones GT, Hannaford PC. Managing low back pain presenting to primary care: where do we go from here? Pain. 2006;122(3):219-222.

7. Downie A, Williams CM, Henschke N, et al. Red flags to screen for malignancy and fracture in patients with low back pain: systematic review. BMJ. 2013;347:f7095.

8. Low Back Pain: Early Management of Persistent Nonspecific Low Back Pain [Internet]. National Collaborating Centre for Primary Care (UK) London, UK: National Institute for Health and Care Excellence; Guidance. 2009. https://pubmed. ncbi.nlm.nih.gov/?term $=$ National + Collaborating + Centre + for + Primary + Care $+\% 28$ UK $\% 29 \% 5$ BCorporate + Author $\% 5$ D

9. Huang W, Cao D, Ma J, et al. Solitary plasmacytoma of cervical spine treatment and prognosis in patients with neurological lesions and spinal instability. Spine (Phila $\mathrm{Pa}$ 1976). 2010;35(8):E278-E284.

10. Kirschblum S, Burns S, Biering-Sorensen FJ. International standards for neurological classification of spinal cord injury (Revised 2011). Spinal Cord Med. 2011;34(6):535-546.

11. Röpke EF, Theissig F, Ulrich G. Solitary plasmacytoma of thoracic vertebra in a woman with Lynch syndrome: a case report. Int J Surg Case Rep. 2019;65:44-47.

Disclosures and COI: The authors received no funding for this study and report no conflicts of interest.

Corresponding Author: K.C. Eseonu, MSc (Oxon), Royal National Orthopaedic Hospital, Stanmore, Brockley Hill, HA7 4LP United Kingdom. Phone: 07837897720; Email: kelechi.eseonu@ doctors.org.uk.

Published 28 August 2020

This manuscript is generously published free of charge by ISASS, the International Society for the Advancement of Spine Surgery. Copyright @ 2020 ISASS. To see more or order reprints or permissions, see http://ijssurgery.com. 